\title{
ANALISIS PEMILIHAN MODA TRANSPORTASI MENUJU BANDARA SOEKARNO HATTA MENGGUNAKAN MOBIL PENUMPANG DAN KERETA API
}

\author{
Dhinahadi Vitriyana ${ }^{1}$, Eva Azhra Latifa ${ }^{2}$ \\ 1,2 Jurusan Teknik Sipil, Politeknik Negeri Jakarta, Kampus Baru UI, 16424. \\ e-mail:1'dhinahaaad@gmail.com,2evaalmy@gmail.com
}

\begin{abstract}
Inadequate access to Soekarno Hatta Airport, only via Prof. Sedyatmo Tollroad and the high volume of vehicles especially passanger car often cause traffic jams during rush hour. The government added access to Soekarno Hatta Airport by operating airport trains. This research aims to analyze the characteristics of passenger car users and airport train users, analyze the opportunity of mode choice between that two modes, and determine the airport trains service according to the users. The data obtained by distributing questionnaires to passenger car users and airport train users. The characteristics of users of each mode were analyzed using descriptive statistics. To determine the probability of moda choice, the binary logit difference model is used with the help of multiple linear regression. Airport train user perceptions of airport train facilities and services were analyzed using a Likert scale. The characteristics of passenger car users are women, age $<25$ years old, educated bachelor degree, income $<R p$. 3,000,000 with the purpose of a family visit. The characteristics of airport train users are men, aged $<25$ years old, educated bachelor degree, earn Rp. 3,000,000 - Rp. 5,000,000 that travel with the aim of business/work. Probabilities for passenger cars were $85.98 \%$, while airport train probabilities were $14.014 \%$. The level of airport train services in aspect of safety and convenience is in a good category, and aspects of comfort and reliability are categorized very well
\end{abstract}

Key words : binary logit difference, characteristic of trip users, Likert scale, transportation moda choice

\begin{abstract}
ABSTRAK
Akses menuju Bandara Soekarno Hatta yang belum memadai yaitu hanya via Jalan Tol Prof. Sedyatmo dan tingginya volume kendaraan jenis mobil penumpang sering mengakibatkan terjadinya kemacetan lali lintas pada jam-jam sibuk. Pemerintah menambah akses menuju Bandara Soekarno Hatta dengan mengoperasikan kereta api bandara. Penelitian ini bertujuan untuk menganalisis karakteristik pelaku perjalanan mobil penumpang dan kereta api bandara, menganalisis peluang pemilihan moda antara kedua moda tersebut, dan menentukan kelayanan kereta api bandara menurut masyarakat pengguna. Data diperoleh dasi hasil penyebaran kuesioner kepada pengguna kereta api bandara danmobil penumpang. Karakteristik pelaku perjalanan masing-masing moda dianalisis menggunakan statistik deskriptif. Untuk mengetahui peluang pemilihan moda digunakan model logit biner selisih dengan bantuan persamaan regresi linear berganda. Persepsi pengguna kereta api bandara terhadap fasilitas dan kelayanan kereta api bandara dianalisis menggunakan skala Likert. Karakteristik umum pengguna mobil penumpang adalah wanita, berusia $<25$ tahun, berpendidikan S1/D4, berpendapatan <Rp. 3.000.000 dengan tujuan perjalanan kunjungan keluarga. Karakteristik umum pengguna KA bandara adalah laki-laki, usia $<25$ tahun, berpendidikan S1/D4, berpendapatan Rp. 3.000.000 - Rp. 5.000.000 yang melakukan perjalanan dengan tujuan dinas/bisnis/kerja. Peluang mobil penumpang yang diperoleh sebesar 85,986\%, sedangkan peluang KA bandara 14,014\%. Tingkat pelayanan KA bandara dalam aspek keamanan dan kemudahan berkategori baik, dan aspek kenyamanan dan keandalan berkategori sangat baik.
\end{abstract}

Katakunsi : karakteristik pelaku perjalanan, logit biner selisih, pemilihan moda transportasi, skala Likert

PENDAHULUAN

Bandara Soekarno Hatta merupakan salah satu gerbang penghubung
Indonesia dengan dunia yang memegang peranan penting dalam pergerakan perekonomian secara global. Menurut Airport Council International 
(ACI), penumpang Bandara Soekarno Hatta pada tahun 2017 sebanyak 63.015.620 orang. Hal ini membuat Bandara Soekarno Hatta menjadi bandara tersibuk di Indonesia.

Kendati demikian, akses menuju bandara hanya dapat dijangkau via Jalan Tol Prof. Dr. Sedyatmo dan jalan umum daerah Rawa Bokor. Jalan Tol Prof. Dr. Sedyatmo terintegrasi dengan Jalan Tol Dalam Kota dan Jalan Tol Lingkar Luar Jakarta dengan volume kendaraan yang tinggi yang mengakibatkan sering terjadinya kemacetan pada jam sibuk. Selain permasalahan kemacetan, pada tahun 2002 dan 2008 Jalan Tol Prof. Dr. Sedyatmo lumpuh total dan terpaksa ditutup karena akses utama menuju Bandara Soekarno ini terendam banjir [1].

Untuk mencegah kejadian tersebut terulang kembali, pemerintah merencanakan untuk membangun akses alternatif dari dan menuju Bandara Soekarno Hatta yaitu kereta api. Penambahan moda transportasi menuju Bandara Soekarno Hatta berikut kelengkapan pelayanannya apakah dapat menarik pengguna mobil penumpang untuk beralih menggunakan kereta api bandara akan dibahas pada penelitian ini dengan tujuan untuk menganalisis karakteristik pelaku perjalanan antara mobil penumpang dan kereta api menuju Bandara Soekarno Hatta, menganalisis peluang pemilihan moda antara mobil penumpang dan kereta api menuju Bandara Soekarno Hatta, dan menentukan kelayanan kereta api bandara menurut masyarakat pengguna.

\section{Moda Transportasi}

Moda berasal dari "modus" yaitu segala sesuatu yang dapat dilihat fisiknya. Untuk transportasi artinya juga demikian tetapi lebih ditekankan pada bagaiamana teknik atau cara pindah seseorang atau barang dari titik asal ke titik tujuan. Banyak terdapat alat transportasi dengan teknik berbeda-beda untuk melayani perpindahan orang atau barang dari titik asal ke titik tujuan. Salah satu pembagian moda transportasi adalah berdasarkan sifat pelayanannya, yaitu moda transportasi pribadi dan moda transportasi umum. Menurut Miro (2012), moda transportasi pribadi merupakan bentuk alat transportasi yang pelayanannya hanya diperuntukkan bagi perorangan yang biaya pemeliharaan dan bahan bakarnya menjadi tanggungan si pemakai angkutan pribadi itu sendiri. Sedangkan moda transportasi umum merupakan alat transportasi yang pelayanannya ditujukan untuk sejumlah orang secara bersama-sama [2].

\section{Pemilihan Moda}

Menurut Oktaviani dan Saputra (2015) pemilihan moda (moda split) dapat didefinisikan sebagai pembagian dari perjalanan yang dilakukan oleh pelaku perjalanan ke dalam moda yang tersedia dengan berbagai faktor yang mempengaruhi [3]. Wulansari pada 2016 menyatakan bahwa dalam pemilihan moda transportasi, pengambil keputusan (konsumen) cenderung memaksimalkan utilitas suatu pilihan. Sehingga alternatif moda yang mempunyai utilitas yang tertinggi memiliki peluang besar untuk dipilih [4] Faktor-faktor yang mempengaruhi pemilihan moda adalah ciri pengguna jalan, ciri pergerakan, ciri fasilitas moda transportasi, dan ciri kota atau zona.

\section{Karakteristik Pelaku Perjalanan}

Karakteristik pengguna dipengaruhi oleh karakteristik sosial ekonomi meliputi; penghasilan, kepemilikan kendaraan, ras dan suku, jenis kelamin, umur, pekerjaan. Faktor lainnya tergantung juga dari atribut perjalanan 
meliputi; tujuan perjalanan seperti untuk bekerja, liburan, kunjungan keluarga atau lainnya, waktu perjalanan, seperti hari, minggu,bulan atau perjalanan tahunan. Perjalanan bekerja misalnya rutinitas yang dilakukan, perjalanan mingguan atau bulanan juga mungkin dilakukan untuk bekerja karena tugas di luar kota, sedangkan perjalanan tahunan biasanya merupakan perjalanan liburan. Lokasi yang merupakan karakteristik yang akan membentuk suatu bangkitan atau tarikan tertentu, dan panjang perjalanan [5].

\section{Pelayanan Transportasi Umum}

Menurut Anggoman pada 2007 [6] kualitas pelayanan merupakan suatu kondisi atau karakteristik dari angkutan umum yang diharapkan oleh pengguna yang terdiri dari:

- Keselamatan, meliputi keselamatan pada waktu menggunakan angkutan umum dan pada waktu kendaraan berhenti.

- Kenyamanan, meliputi kenyamanan fisik penumpang, keindahan dan lingkungan.

- Kemudahan pencapaian meliputi distribusi rute yang menjangkau seluruh wilayah, kapasitas kendaraan, frekuensi pelayanan dan pengoperasian jadwal, identifikasi tempat perhentian dan distribusi papan informasi.

- Keandalan, elemen ini tergantung dari penyediaan pelayanan khusus yang diberikan oleh operator.

\section{Model Pemilihan Moda}

Model logit-biner digunakan untuk memodel pemilihan moda yang terdiri dari dua alternatif moda. Terdapat dua jenis model yang sering digunakan, yaitu model selisih dan model nisbah. Kedua model ini sangat ditentukan oleh persepsi seseorang membandingkan biaya perjalanan atau waktu tempuh dalam memilih moda yang akan digunakannya [7].

Dalam studi ini digunakan model logit biner selisih dengan persamaan:

$$
\begin{array}{ll}
P(i)=\frac{1}{1+e^{U j-U i}} & {[\text { Persamaan 1] }} \\
P(j)=\frac{e^{U j-U i}}{1+e^{U j-U i}} & {[\text { Persamaan 2] }}
\end{array}
$$

dimana:

P(i) : peluang moda ke i untuk dipilih

$P(j)$ : peluang moda ke j untuk dipilih

Ui,Uj: nilai parameter atau nilai kepuasan menggunakan moda i dan moda j

e : eksponensial

Model logit biner dapat diselesaikan dengan menggunakan metode regresi linear. Model analisis regresi linier adalah metode statistik yang dapat digunakan untuk mempelajari hubungan antarsifat permasalahan yang sedang diselidiki. Model analisis regesi linier berganda memodelkan hubungan antar dua variabel [8].

$\mathrm{Y}=\mathrm{a}_{0}+\mathrm{a}_{1} \mathrm{X}_{1}+\mathrm{a}_{2} \mathrm{X}_{2}$ [Persamaan 3]

dimana:

Y : variabel tidak bebas

$\mathrm{X}_{1}, \mathrm{X}_{2}$ : variabel bebas

$\mathrm{a}_{0} \quad$ : konstanta regresi

$\mathrm{a}_{1}, \mathrm{a}_{2}$ : koefisien regresi

\section{Skala Likert}

Skala Likert merupakan metode pengukuran yang digunakan untuk mengukur sikap, pendapat, dan persepsi seseorang atau kelompok orang tentang fenomena sosial. Pengukuran ditentukan berdasarkan hasil skor perhitungan skala Likert pada masingmasing item yang dianalisis [9]. 


\section{METODE PENELITIAN}

\section{Data}

Pengambilan data pada studi ini terdiri dari data primer dan data sekunder. Data primer diperoleh dari survey biaya dan waktu perjalanan sepanjang rute Stasiun Sudirman Baru (BNI City) menuju Bandara Soekarno Hatta dan penyebaran kuesioner yang dilakukan di Bandara Soekarno Hatta untuk pengguna mobil penumpang dan Stasiun Sudirman Baru (BNI City) untuk pengguna kereta api bandara. Kuesioner yang dibagikan terdiri atas 3 bagian. Pertama, bentuk pertanyaan yang ditujukan untuk mengetahui karakteristik pelaku perjalanan berupa usia, jenis kelamin, jenjang pendidikan, penghasilan, dan tujuan perjalanan. Bagian kedua, pertanyaan ditujukan untuk mengetahui kecenderungan responden terhadap keaadan aktual atribut yang mempengaruhi pemilihan moda yaitu biaya dan waktu perjalanan. Bagian ketiga berisi beberapa pertanyaan mengenai fasilitas kereta bandara dalam beberapa aspek untuk pengguna kereta api bandara dan pertanyaan pertimbangan pengguna mobil penumpang jika ingin menggunakan kereta api bandara.

Data sekunder yang diperlukan adalah volume kendaraan di Jalan Tol Dalam Kota dan Jalan Tol Sedyatmo, jadwal keberangkatan kereta api bandara ke Bandara Soekarno Hatta, dan volume penumpang harian kereta api bandara.

\section{Analisis data}

Metode analisis statistik deskriptif digunakan untuk mengetahui karakteristik pelaku perjalanan menggunakan aplikasi Microsoft Excel. Untuk mengetahui peluang pemilihan moda digunakan model logit biner selisih menggunakan Persamaan 1 dan Persamaan 2 dengan bantuan persamaan regresi linear berganda Persamaan 3 yang dicari menggunakan SPSS v.22.0 Persepsi pengguna kereta api bandara terhadap fasilitas dan pelayanan kereta api bandara dianalisis menggunakan skala Likert. Masing-masing item dalam beberapa aspek dihitung skor penilaiannya agar diketahui tingkat pelayanannya.

\section{HASIL dan PEMBAHASAN}

\section{Analisis Karakteristik Pelaku Perjalanan}

Berdasarkan Gambar 1. pengguna mobil penumpang sebanyak 65\% adalah wanita dan $35 \%$ adalah pria. Sedangkan pengguna kereta api bandara sebanyak $42 \%$ adalah wanita dan 58\% adalah pria. Dari hasil tersebut, dapat dikatakan ahwa penumpang mobil penumpang kebanyakan adalah wanita dan pengguna kereta api bandara adalah pria. Hal ini mungkin dikarenakan mobil penumpang lebih aman untuk wanita terlebih lagi jika membawa barang bawaan.

Pada Gambar 2. Baik mobil penumpang maupun kereta api bandara didominasi pengguna yang berumur kurang dari 25 tahun sebesar $45 \%$ dan $47 \%$. Urutan kedua terbanyak pengguna kereta api adalah berumur 26 - 30 tahun. Hal ini dapat disimpulkan bahwa masyarakat yang berpergian menuju Bandara Soekarno Hatta menggunakan kereta api bandara berada pada usia produktif.

Untuk tingkat pendidikan responden baik pengguna mobil penumpang maupun kereta api bandara adalah S1/D4 dengan nilai masing-masing adalah 34\% dan 52\% seperti pada Gambar 3.

Sebanyak 29\% responden pengguna mobil penumpang memiliki pendapatan per bulan sebesar kurang dari Rp. 3.000.000. Besar pendapatan per bulan untuk pengguna kereta api bandara adalah berada pada kisaran Rp. 3.000.000 - Rp. 5.000 .000 
sebanyak 36\% responden dapat dilihat pada

\section{Gambar 4.}

Dari responden pengguna mobil penumpang sebesar $41 \%$ responden melakukan perjalanan ke Bandara Soekarno Hatta dengan tujuan kunjungan keluarga seperti yang ditunjukkan pada Gambar 5. Sedangkan tujuan pengguna kereta bandara adalah untuk dinas/bisnis/kerja sebanyak 52\%. Hal ini mungkin untuk tujuan dinas/bisnis/kerja lebih efisien menggunakan kereta bandara karena hanya seorang diri, barang bawaan tidak banyak, dan letak Stasiun Sudirman Baru (BNI City) yang strategis pada kawasan perkantoran. Sedangkan tujuan perjalanan kunjungan keluarga lebih mudah menggunakan mobil penumpang karena barang bawaan yang banyak dan membawa anggota keluarga.

\section{Analisis Pemilihan Moda}

Fungsi utilitas masing-masing moda didapatkan dari hasil analisis menggunakan SPSS sebagai berikut:

Fungsi utilitas mobil penumpang:

$\mathrm{U}_{\mathrm{MP}}=-640,351+45,730 \mathrm{X}_{1}-47,541$

$\mathrm{X}_{2}$ [Persamaan 4]

Fungsi utilitas kereta api bandara:

$\mathrm{U}_{\mathrm{KA}}=-473,836+7,058 \mathrm{X}_{2}$

[Persamaan 5]

Analisis selanjutnya adalah model logit biner selisih untuk mengetahui peluang masing-masing moda. Peluang yang dicari adalah pada saat waktu jam sibuk, tidak sibuk, dan secara umum yaitu besar biaya dan waktu rata-rata masingmasing moda. Besar biaya dan waktu didapat dari hasil survey yang telah dilakukan.
- Jam Sibuk

Dengan "Persamaan 4" didapatkan nilai utilitas pada jam sibuk, $\mathrm{U}_{\mathrm{MP}}=44,97172$

Dengan "Persamaan 5" didapatkan nilai utilitas pada jam sibuk, $\mathrm{U}_{\mathrm{KA}}=157,855$

Selanjutnya dimasukkan ke dalam "Persamaan 1" dan "Persamaan 2"

$$
\begin{aligned}
& \mathrm{P}_{\mathrm{MP}}=\frac{1}{1+\mathrm{e}^{\mathrm{U}_{\mathrm{KA}}-\mathrm{U}_{\mathrm{MP}}}}=0 \% \\
& \mathrm{P}_{\mathrm{KA}}=\frac{\mathrm{e}^{\mathrm{U}_{\mathrm{KA}}-\mathrm{U}_{\mathrm{MP}}}}{1+\mathrm{e}^{\mathrm{U}_{\mathrm{KA}}-\mathrm{U}_{\mathrm{MP}}}}=100 \%
\end{aligned}
$$

Berdasarkan hasil analisis diatas dapat dikatakan bahwa pada saat jam sibuk, orang akan lebih memilih kereta api (100\%) dibandingkan mobil penumpang (0\%).

\section{- Jam Tidak Sibuk}

Dengan "Persamaan 4" didapatkan nilai utilitas pada jam sibuk, $\mathrm{U}_{\mathrm{MP}}=145,21$

Dengan "Persamaan 5" didapatkan nilai utilitas pada jam sibuk, $\mathrm{U}_{\mathrm{KA}}=50,57$

Selanjutnya dimasukkan ke dalam "Persamaan 1" dan "Persamaan 2"

$$
\begin{aligned}
& \mathrm{P}_{\mathrm{MP}}=\frac{1}{1+\mathrm{e}^{\mathrm{U}_{\mathrm{KA}}-\mathrm{U}_{\mathrm{MP}}}}=100 \% \\
& \mathrm{P}_{\mathrm{KA}}=\frac{\mathrm{e}^{\mathrm{U}_{\mathrm{KA}}-\mathrm{U}_{\mathrm{MP}}}}{1+\mathrm{e}^{\mathrm{U}_{\mathrm{KA}}-\mathrm{U}_{\mathrm{MP}}}}=0 \%
\end{aligned}
$$

Berdasarkan hasil analisis diatas dapat dikatakan bahwa pada saat jam tidak sibuk, orang akan lebih memilih mobil penumpang (100\%) dibandingkan kereta api (0\%).

\section{- Secara Umum}

Dengan "Persamaan 4" didapatkan nilai utilitas pada jam sibuk, $\mathrm{U}_{\mathrm{MP}}=99,39$

Dengan "Persamaan 5" didapatkan nilai utilitas pada jam sibuk, $\mathrm{U}_{\mathrm{KA}}=97,58$

Selanjutnya dimasukkan ke dalam "Persamaan 1" dan "Persamaan 2" 
$\mathrm{P}_{\mathrm{MP}}=\frac{1}{1+\mathrm{e}^{\mathrm{U}_{\mathrm{KA}}-\mathrm{U}_{\mathrm{MP}}}}=85,986 \%$

$\mathrm{P}_{\mathrm{KA}}=\frac{\mathrm{e}^{\mathrm{U}_{\mathrm{KA}}-\mathrm{U}_{\mathrm{MP}}}}{1+\mathrm{e}^{\mathrm{U}_{\mathrm{KA}}-\mathrm{U}_{\mathrm{MP}}}}=14,014 \%$

Berdasarkan hasil analisis diatas dapat dikatakan bahwa secara umum ketika sekelompok orang akan melakukan perjalanan menuju Bandara Soekarno Hatta dari daerah Sudirman sebanyak 85,986 \% akan memilih moda transportasi mobil penumpang dan sisanya sebanyak $14,014 \%$ akan memilih menggunakan kereta api bandara.

\section{Analisis Persepsi Pengguna Kereta Api Bandara}

Persepsi pengguna kereta api bandara dianalisis berdasarkan aspek keamanan, kemudahan, kenyamanan, dan keandalan. Skala Likert yang digunakan adalah 4 skala dengan interval skor sebagai berikut:

$0-25 \% \quad$ : $\quad$ Sangat $\quad$ Tidak Setuju/Sangat Tidak Baik

$26-50 \%$ : Tidak Setuju/Tidak Baik

$51-75 \%$ : Setuju/Baik

$76-100 \%$ : Sangat Setuju/Sangat Baik

Hasil skor untuk masing-masing aspek dapat dilihat pada Tabel 1., Tabel 2., Tabel 3., dan Tabel 4.

\section{KESIMPULAN}

Berdasarkan hasil analisis pemilihan moda transportasi antara mobil penumpang dan kereta api bandara menuju Bandara Soekarno Hatta dapat diambil beberapa kesimpulanyaitu karakteristik pelaku perjalanan moda mobil penumpang adalah $65 \%$ wanita dengan umur di bawah 25 tahun, berpendidikan S1/D4, memiliki pendapatan di bawah Rp. 3.000.000 yang melakukan perjalanan dengan tujuan kunjungan keluarga. Sedangkan karakteristik pelaku perjalanan moda kereta api bandara 58\% adalah laki-laki dengan umur di bawah 25 tahun, berpendidikan S1/D4, memiliki pendapatan Rp. 3.000 .000 Rp.5.000.000 yang melakukan perjalanan dengan tujuan dinas/bisnis/kerja. Peluang moda transportasi mobil penumpang dan kereta api bandara dengan menggunakan model logit biner selisih adalah pada jam sibuk P(MP) $0 \%$ dan P(KA) $100 \%$, pada jam tidak sibuk P(MP) 100\% dan P(KA) 0\%, dan secara umum $\mathrm{P}(\mathrm{MP}) \quad 85,986 \%$ dan $\mathrm{P}(\mathrm{KA})$ 14,014\%. Tingkat pelayanan berdasarkan persepsi masyarakat pengguna kereta api bandara untuk aspek keamanan dan kemudahan berada pada kategori Baik, dan aspek kenyamanan serta aspek keandalan berkategori Sangat Baik.

\section{DAFTAR PUSTAKA}

[1] https://tirto.id/penantian-panjangkereta-bandara-soekarno-hatta-cAnm 2017. Penantian Panjang Kereta Bandara Soekarno-Hatta. 21 November 2017.

[2] Miro, Fidel. 2012. Pengantar Sistem Transportasi. Jakarta: Penerbit Erlangga.

[3] Oktaviani dan Andre Yuli Saputra. 2015. Alternatif Pemilihan Moda Transportasi Umum (Studi Kasus: Bus Dan Kereta Api Trayek Kota Padangkota Pariaman). Annual Civil Engineering Seminar 2015, Pekanbaru.ISBN: 978-979-792-6366.

[4] Wulansari, Dwi Novi. 2016. Kompetisi Pemilihan Moda Angkutan Penumpang Berdasarkan Model Logit Binomial-Selisih Dan Logit Binomial Nisbah. Jurnal Fropil Vol. 4 Nomor 1 Jan-Juni 2016.

[5] Mulyono, Tri. 2003. Analisis Pemilhan Moda Angkutan Kereta 
Api Berdasarkan Faktor Tingkat Pelayanan Dan Biaya Perjalanan Studi Kasus: Pada Kelas Argo (Eksekutif) Dilintas Jawa. Tesis Program Pascasarjana Bidang Ilmu Teknik Kekhususan Transportasi Program Studi Teknik Sipil Universitas Indonesia.

[6] Anggoman, Johan Paul Engelberthus. 2007. Studi Tingkat Pelayanan Angkutan Umum Damri di Kota Manado. Tesis Program Pascasarjana Magister Teknik
Pembangunan Wilayah dan Kota Universitas Dipenogoro.

[7] Tamin, O. Z. 2003. Perencanaan dan Pemodelan Transportasi. Bandung: Penerbit ITB.

[8] Suthanaya, Putu Alit. 2012. Analisis Faktor-Faktor yang Mempengaruhi Pemilihan Moda di Kota Denpasar (Studi Kasus: Koridor Jl. Raya Sesetan). KoNTekS 6 Universitas Trisakti, 1 - 2 November 2012.

[9] Sugiyono, 2012. Metode Penelitian Kuantitatif, Kualitatif, dan $R \& D$. Bandung: Alfabeta..

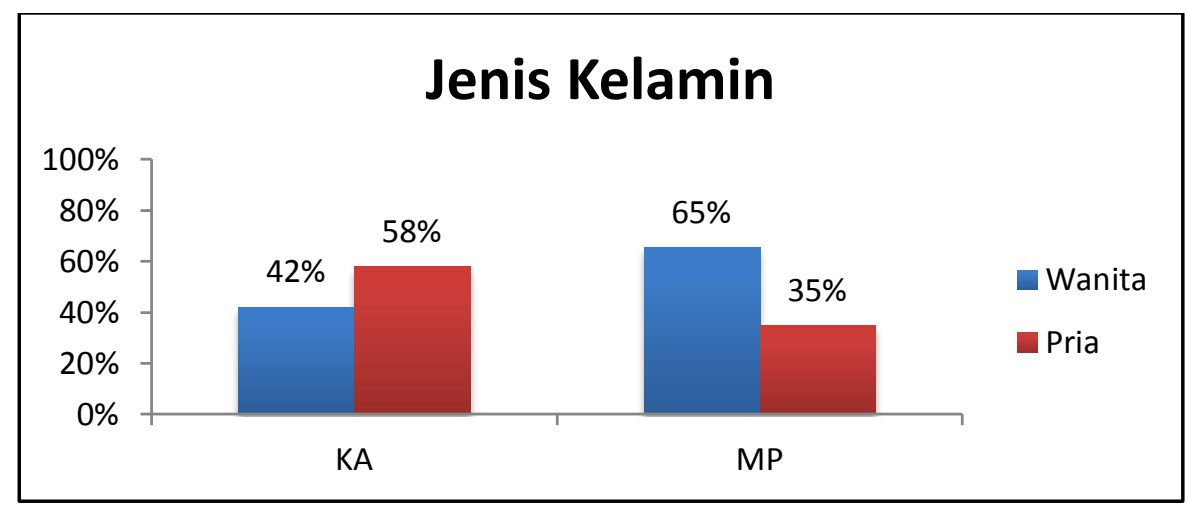

Gambar 1. Diagram karakteristik jenis kelamin

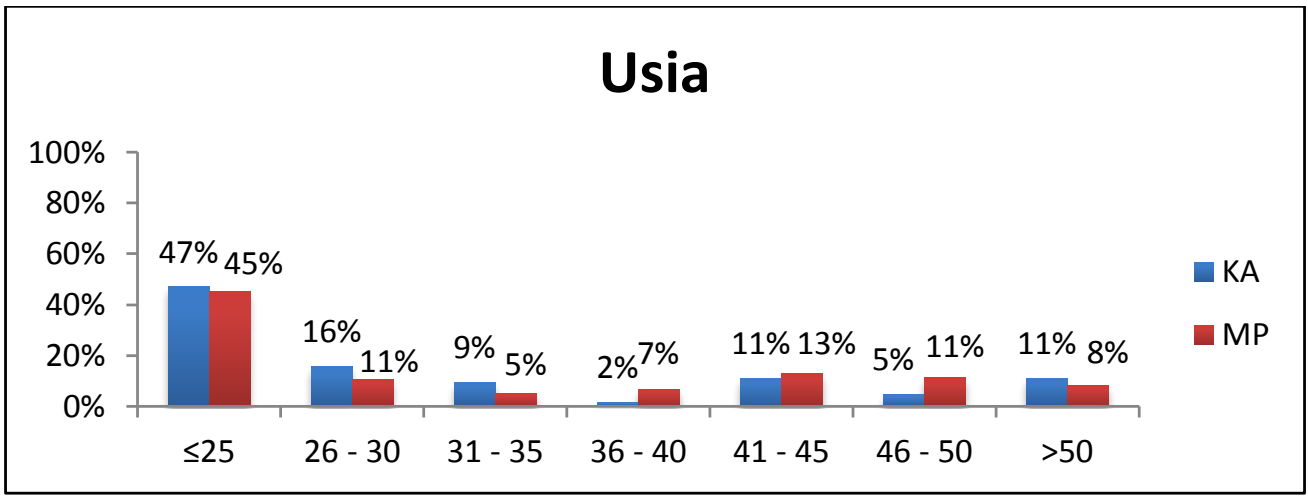

Gambar 2. Diagram karakteristik usia 


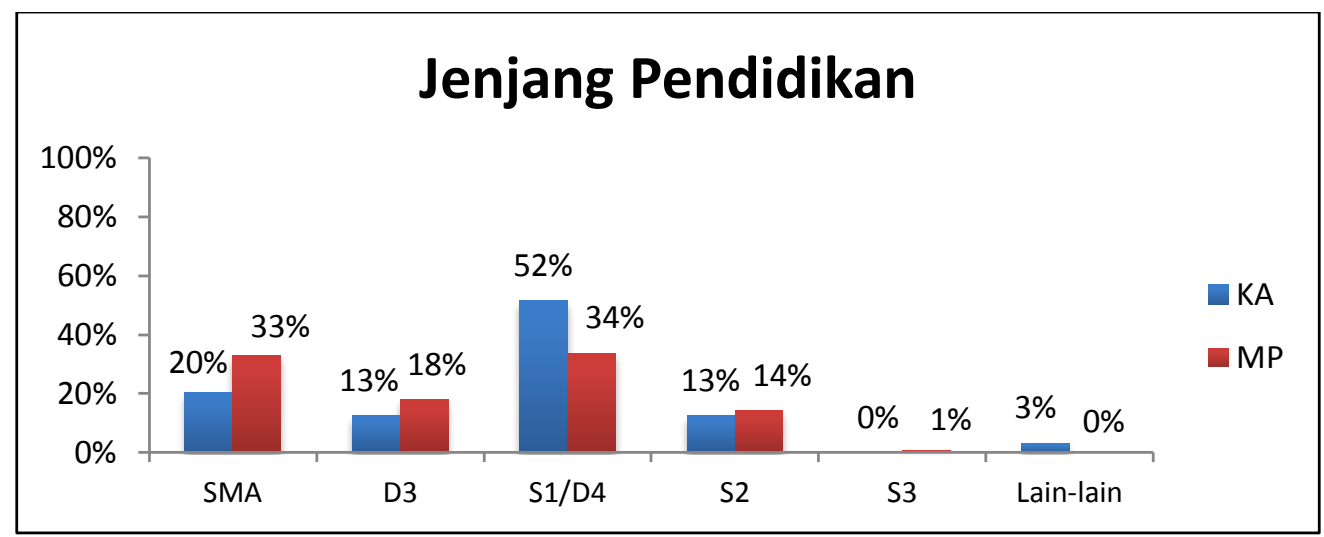

Gambar 3. Diagram karakteristik pendidikan

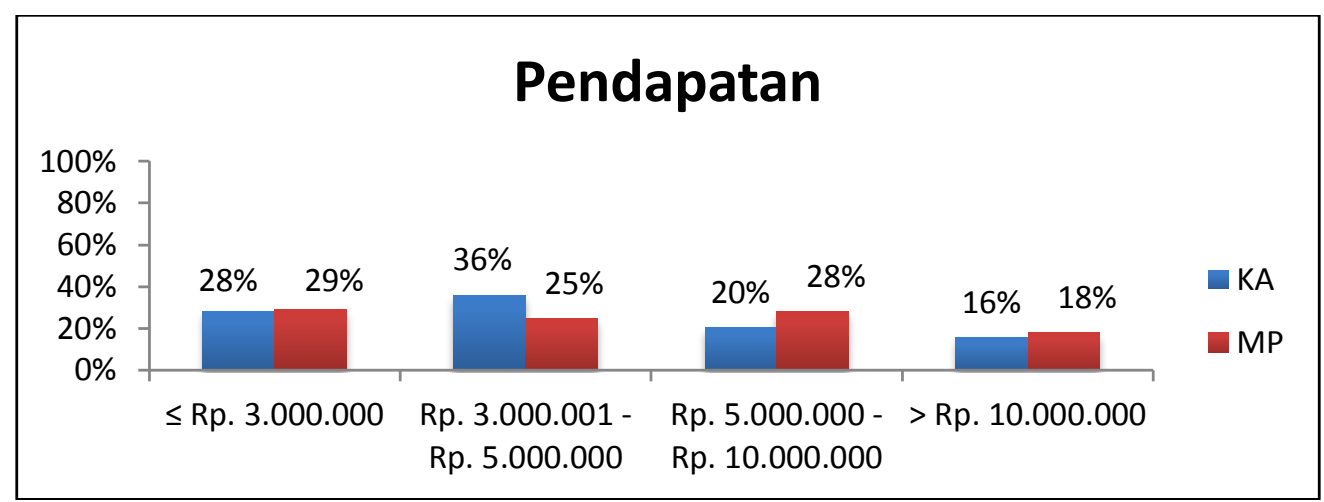

Gambar 4. Diagram karakteristik pendapatan

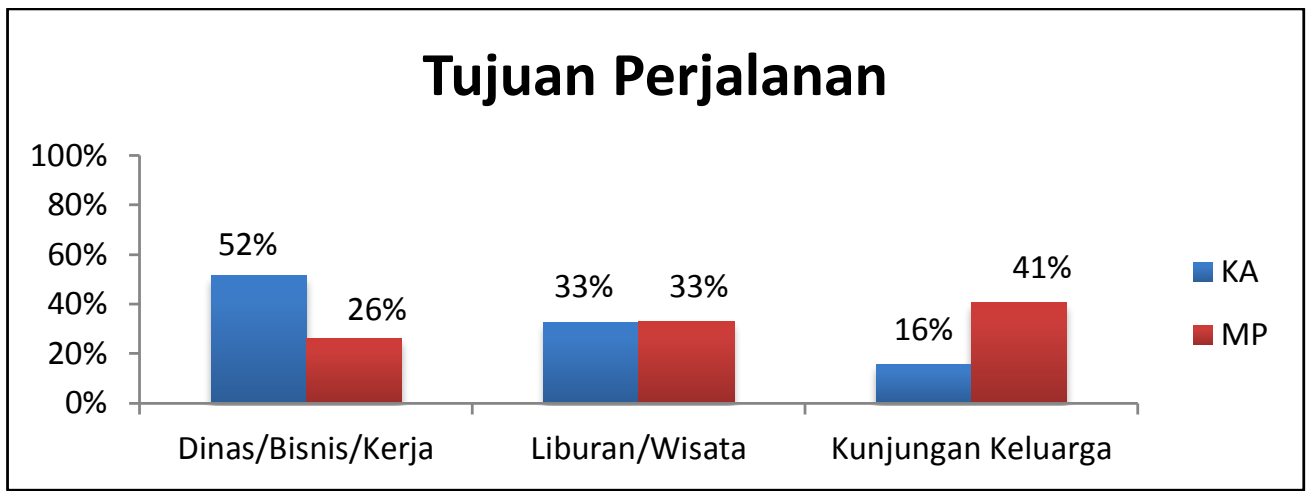

Gambar 5. Diagram karakteristik tujuan perjalanan

Tabel 1. Aspek keamanan

\begin{tabular}{lcc}
\hline \multicolumn{1}{c}{ Pertanyaan/Pernyataan } & Skor & Kategori \\
\hline Saya merasa aman meletakkan barang pada rak di dalam gerbong & & \\
kereta. & & \\
Saya merasa aman meninggalkan barang Saya saat Saya sedang & & \\
berada di mushala atau toilet di Stasiun Sudirman Baru (BNI 61,875\% & Baik \\
City). & & \\
Saya merasa perlu akan adanya fasilitas penitipan barang di & & \\
Stasiun Sudirman Baru (BNI City). & & \\
\hline
\end{tabular}


Tabel 2. Aspek kemudahan

\begin{tabular}{|c|c|c|}
\hline Pertanyaan/Pernyataan & Skor & Kategori \\
\hline $\begin{array}{l}\text { Menurut Saya, Stasiun Sudirman Baru (BNI City) mudah } \\
\text { dijangkau. } \\
\text { Menurut Saya, proses pembelian tiket Kereta Bandara dengan } \\
\text { Vending Machine mudah untuk dilakukan. } \\
\text { Menurut Saya, pembelian tiket melalui aplikasi sangat mudah dan } \\
\text { efisien karena Saya langsung mendapatkan barcode untuk gate-in } \\
\text { tanpa harus registrasi tiket kembali di Stasiun. } \\
\text { Saya tidak masalah untuk transaksi pembelian tiket dengan sistem } \\
\text { pembayaran cashless atau non-tunai. } \\
\text { Saya merasa mudah dalam mencari informasi apapun saat sedang } \\
\text { di Stasiun Sudirman Baru (BNI City). } \\
\text { Saya merasa mudah dalam mencari informasi mengenai tempat } \\
\text { pemberhentian selanjutnya dan waktu tiba di bandara saat sedang } \\
\text { berada di dalam kereta bandara. }\end{array}$ & $73,07 \%$ & Baik \\
\hline
\end{tabular}

Tabel 3. Aspek kenyamanan

\begin{tabular}{lcc}
\hline \multicolumn{1}{c}{ Pertanyaan/Pernyataan } & Skor & Kategori \\
\hline $\begin{array}{l}\text { Kondisi tempat duduk di dalam kereta ergonomis/nyaman. } \\
\text { Jarak antar tempat duduk di dalam kereta agak berjauhan }\end{array}$ & \\
sehingga ada ruangan untuk kaki yang nyaman. & & \\
$\begin{array}{l}\text { Kondisi ruang tunggu di Stasiun Sudirman Baru (BNI City) } \\
\text { nyaman, memadai dan luas. }\end{array}$ & \\
$\begin{array}{l}\text { Saya tidak masalah dengan sirkulasi atau proses dari pembelian } \\
\text { tiket sampai naik kereta bandara yang mengharuskan saya untuk } \\
\text { naik dan turun lantai di Stasiun Sudirman Baru (BNI City). } \\
\text { Adanya ruangan khusus untuk merokok (smooking room) yang } \\
\text { nyaman di Stasiun Sudirman Baru (BNI City). }\end{array}$ & $\begin{array}{c}\text { Sangat } \\
\text { Baik }\end{array}$ \\
\hline
\end{tabular}

Tabel 4. Aspek keandalan

\begin{tabular}{lcc}
\hline \multicolumn{1}{c}{ Pertanyaan/Pernyataan } & Skor & Kategori \\
\hline $\begin{array}{l}\text { Kereta berangkat dari Stasiun Sudirman Baru (BNI City) sesuai } \\
\text { dengan jadwal keberangkatan. }\end{array}$ & \\
$\begin{array}{l}\text { Kereta tiba di Stasiun Bandara Soekarno Hatta sesuai dengan } \\
\text { jadwal tiba. }\end{array}$ & Sangat \\
$\begin{array}{l}\text { Saya dapat mengkonfirmasi langsung jika ada keterlambatan atau } \\
\text { pembatalan kereta. }\end{array}$ & & Baik \\
$\begin{array}{l}\text { Saya tidak masalah dengan aturan penutupan pembelian tiket } 7 \\
\text { menit sebelum jam keberangkatan kereta. }\end{array}$ & \\
\hline
\end{tabular}


Dhinahadi Vitriyana dan Eva Azhra Latifa, Analisis Pemilihan Moda... 